\title{
Conserved and variable domains within divergent RNase P RNA gene sequences of Prochlorococcus strains
}

\footnotetext{
${ }^{1}$ Institut für Biochemie, Bayerische JuliusMaximilians-Universität, Biozentrum, Am Hubland, D-97074 Würzburg, Germany

2 Institut für Biologie/Genetik, Humboldt-Universität, Chausseestrasse 117, D-10115 Berlin, Germany
}

\author{
Astrid Schön, ${ }^{1} \dagger$ Christiane Fingerhut ${ }^{1}$ and Wolfgang R. Hess ${ }^{2}$ \\ Author for correspondence: Wolfgang R. Hess. Tel: +49 0302093 8144. Fax: +49 03020938139. \\ e-mail: wolfgang.hess@rz.hu-berlin.de
}

\begin{abstract}
RNase P RNA gene (rnpB) sequences were PCR-amplified from different members of the Prochlorococcus group. Aligned nucleotide sequences revealed a variance of up to $27 \%$ for $r n p B$. Comparative secondary structure analysis showed that domains P12, P18 and P19 of these novel ribozyme sequences in particular are highly divergent. Thus, these regions in RNase P RNA might serve as potential targets for deoxyoligonucleotide primers for the identification of specific genotypes of Prochlorococcus and for probing field populations. Phylogenetic trees constructed from RNase P RNA sequences were similar to, but not fully congruent with, those derived previously using sequences of the $16 S$ rRNA gene. However, the application of $r n p B$ sequences allowed a better resolution within clades of very closely related genotypes. As is known from $16 S$ rRNA-based phylogenetic trees, sequences from individual strains clustered according to their physiology and the conditions at the original site of isolation, rather than their geographical origin. All sequences obtained from high-light-adapted strains formed a single coherent clade, as did the four sequences from low-light-adapted strains that were previously isolated from the North Atlantic and the subtropical North Pacific. This suggests a remarkable genetic stability of Prochlorococcus genotypes that thrive under identical ecological conditions.
\end{abstract}

Keywords: ribonuclease P RNA gene sequence, cyanobacteria, Prochlorococcus, Synechococcus, phylogeny

\section{INTRODUCTION}

RNase $\mathrm{P}$ is a ubiquitous enzyme essential for tRNA maturation. In bacteria, the catalytic site resides in the RNA subunit, which is able to perform precise endonucleolytic cleavage of tRNA precursors to yield the mature 5' end (Frank \& Pace, 1998; Pace \& Brown, 1995; Schön, 1999), whereas the small, basic protein

Published online ahead of print on 3 December 2001 as DOI 10.1099/ijs.0.01983-0.

A structure-optimized alignment of Prochlorococcus RNase P RNA sequences is available as supplementary material in IJSEM Online (http://ijs.sgmjournals.org/).

† Present address: Institut für Biochemie, Universität Leipzig, Talstrasse 33, D-04103 Leipzig, Germany.

Abbreviations: $\mathrm{HL}$, high-light-adapted; LL, low-light-adapted.

The EMBL accession numbers for the RNase P RNA gene sequences reported in this paper are AJ272218-AJ272226 (see Fig. 3). subunit improves catalytic efficiency by binding the pre-tRNA 5' flank (Crary et al., 1998; Niranjanakumari et al., 1998). The RNA component of RNase $\mathrm{P}$ is encoded by $\operatorname{rnp} B$, the protein by rnp $A$.

Sequences of $r n p B$ from different bacterial groups vary considerably in sequence and length. In addition to several short patches containing invariant nucleotides, only two stretches of sequence conservation are consistently present. Despite this variability, co-variation analysis of sequences covering the whole range of phylogenetic groups has made possible the definition of a universally conserved minimal consensus structure for these catalytically active RNAs (Haas et al., 1994). According to this model, the two conserved regions constitute a long-range base pairing ( $\mathrm{P} 4)$ involved in maintaining the three-dimensional structure of the ribozyme (Chen et al., 1998; Harris et al., 1994, 1997; Westhof \& Altman, 1994; Westhof et al., 1996). 
Table 1. List of strains used in this study

\begin{tabular}{|llcl|}
\hline \multicolumn{1}{|c|}{ Strain } & \multicolumn{1}{c|}{ Site of isolation } & Ecological type & \multicolumn{1}{c|}{ Reference } \\
\hline CCMP $1375^{\mathrm{T}}\left(=\mathrm{SS} 120^{\mathrm{T}}\right)$ & Sargasso Sea & LL & Chisholm et al. (1992) \\
PCC $9511^{\mathrm{T}}$ & Mediterranean Sea & HL & Rippka et al. $(2000)$ \\
NATL1A & North Atlantic & LL & Scanlan et al. $(1996)$ \\
NATL2A & North Atlantic & LL & Scanlan et al. $(1996)$ \\
TAK9803-2 & South Pacific Ocean, Takapoto Lagoon & HL & Garczarek et al. $(2000)$ \\
TATL1B & South Atlantic & HL & Scanlan et al. $(1996)$ \\
TATL2 & South Atlantic & HL & Scanlan et al. $(1996)$ \\
PAC1 & Subtropical North Pacific Ocean & LL & Penno et al. $(2000)$ \\
Synechococcus sp. MINOS1 & Mediterranean Sea & - & - \\
\hline
\end{tabular}

RNase P RNA sequences of related species are more variable than their $16 \mathrm{~S}$ rRNAs. Thus, this ubiquitous RNA could be a very useful tool for a more detailed classification of bacteria, including species still unclassified. Previous comparative analyses of $r n p B$ sequences from natural samples provided important information on the diversity of natural microbial populations (Brown et al., 1996). Sequences and structures of RNase P RNAs were suggested as distinctive markers within Saccharomonospora, the Chlamydiales and actinomycetes and allowed the inference of evolutionary relationships (Cho et al., 1998; Herrmann et al., 2000; Yoon \& Park, 2000). In addition, information about the existing variants of RNase P RNAs provided clues towards the functional relevance of the different domains for the function of the catalytic core (Brown et al., 1996).

Characterization of $r n p B$ and the enzymic activity of RNase P RNA from the cyanobacterium Prochlorococcus marinus subsp. marinus CCMP $1375^{\mathrm{T}}$ (strain $\mathrm{SS}_{120^{\mathrm{T}}}$; Hess et al., 1998) has been reported previously. Picophytoplankton species belonging to the genera Synechococcus and Prochlorococcus are thought to have evolved rapidly and nearly simultaneously (Urbach et al., 1998). Genetic analyses of different Prochlorococcus strains indicated the existence of a strong correlation between phylogeny and physiology in this genus (Moore et al., 1998; Rocap et al., 1999; Scanlan et al., 1996; Urbach \& Chisholm, 1998; Urbach et al., 1998; West \& Scanlan, 1999). The strains of Prochlorococcus that occupy the most distal part of 16S rRNA trees are all adapted to high-light conditions (high-light-adapted, HL) and are characterized by a relatively low chlorophyll $b / a$ ratio. According to such a $16 \mathrm{~S}$ rRNA-based phylogeny, lowlight-adapted (LL) strains belong to at least four different phylogenetic groups, whereas the HL strains can be subdivided into two groups, sometimes called HLI and HLII (West \& Scanlan, 1999).

The knowledge of additional RNase P RNA sequences from members of the genus Prochlorococcus should help to confirm and further resolve phylogenetic relationships within this group. The sequence and structure of nine new RNase P RNA genes from members of the Synechococcus / Prochlorococcus group are described, suggesting variable and conserved regions possibly useful for an analysis of natural samples, and some of the secondary structural elements potentially relevant for catalytic activity are discussed.

\section{METHODS}

Bacterial strains. Cultures of various Prochlorococcus strains (Table 1) were maintained as described previously (PCC 9511 ${ }^{\mathrm{T}}$, TAK9803-2, P. marinus subsp. marinus $\mathrm{SS} 120^{\mathrm{T}}$, NATL1A, NATL2A; Partensky et al., 1999) or DNA was extracted from cells obtained from F. Partensky at the Biological Station in Roscoff, France (TATL1B, TATL2 and Synechococcus MINOS1), or from L. Campbell at the Texas A\&M University, College Station, TX, USA (PAC1). DNA extraction and $r m p B$ amplification from PAC1 was performed with two different DNA samples, one isolated in 1994 and the other in 1998, after clonal diversity of this culture had been recognized on the basis of phycoerythrin sequences (Penno et al., 2000).

DNA amplification and sequencing. Genomic DNA from the different Prochlorococcus strains (Table 1) was amplified either with the primer pair cprp5'/cprp3' (Baum et al., 1996) or the alternative primer set cprp5'-OL (CTGAGGAAAGTCCGGGCT) and cprp3'-OL (GTAAGCCGGGTTCTGTT). The $5^{\prime}$ flanking region of PAC1 rnpB was obtained with the primer pair Pm-F5' (CCCACGACCTACGGTTTAGG) and cprp3'-OL. PCRs were performed with the proof-reading $P f u$ DNA polymerase (Stratagene) in a Hybaid OmniGene PCR incubator $(0.5 \mu \mathrm{M}$ each primer, $200 \mu \mathrm{M}$ each dNTP, 0.05 U Pfu DNA polymerase $\mu 1^{-1}$ and $1-10 \mathrm{ng}$ template DNA in a total volume of $20 \mu \mathrm{l})$. After denaturation for $2 \mathrm{~min}$ at $94{ }^{\circ} \mathrm{C}, 35$ cycles of PCR were performed $\left(30 \mathrm{~s}\right.$ at $94{ }^{\circ} \mathrm{C}, 30 \mathrm{~s}$ of annealing at $61{ }^{\circ} \mathrm{C}, 1 \mathrm{~min}$ at $72^{\circ} \mathrm{C}$ ). PCR products were purified by agarose gel electrophoresis and eluted with a JETquick kit (Genomed), followed by cloning into pUC19 and Escherichia coli DH5 $\alpha$ or JM109 (Baum et al., 1996). DNA was sequenced using an ABI 373 DNA sequencer (Applied Biosystems). Several independent clones were sequenced from all PCR-derived constructs to ensure that the native sequences were obtained. The GCG program package version 9.0 (University of Wisconsin, Madison, USA) was used for data analysis. Sequence alignments were obtained with LINEUP and CLUSTAL W. Homology searches were performed with the programs FASTA or BESTFIT. Preliminary sequence data 
for Prochlorococcus sp. MIT 9313 was obtained from the DOE Joint Genome Institute (http://spider.jgi-psf. org/JGI_microbial/html/).

\section{RESULTS AND DISCUSSION}

Eight different sequences were obtained from the seven cultures of Prochlorococcus investigated and one from a hitherto uncharacterized marine Synechococcus strain (MINOS1). The sequences were 307-335 nt and encompassed about $85 \%$ of the full-length rnpB gene. The Prochlorococcus sequences shared 74-99\% similarity. Interestingly, all Prochlorococcus sequences have about the same degree of identity $(70-75 \%$ in the raw alignment) if compared to the two Synechococcus sequences, MINOS1 and Synechococcus elongatus PCC 6301 (formerly Anacystis nidulans PCC 6301; for details of reclassification, see Herdman et al., 2001). The total genome sequence of Prochlorococcus strain MED4 is now available. Its RNase P RNA sequence is identical to that from $P$. marinus subsp. pastoris $\mathrm{PCC}$ $9511^{\mathrm{T}}$ except for an A-to-T transversion at position 289 of the PCC $9511^{\mathrm{T}} \operatorname{rnp} B$ sequence. Thus, this situation is very similar to the one nucleotide difference found between the two strains in the 16S rRNA gene (Rippka et al., 2000; GenBank acc. no. AF180967) and shows their very high degree of relatedness.

An improved, structure-based alignment was obtained taking into account conserved and variable elements of secondary and tertiary structure. The alignment is available as supplementary material in IJSEM Online (http://ijs.sgmjournals.org/). It should be noted here that our alignment of the P12 region differs slightly from that suggested in the RNase P database (Brown, 1999); however, these alternative alignments do not lead to significant differences in phylogenetic trees (not shown).

Two different sequences, PAC1A and PAC1B (identity $95 \%$ ), were amplified from a single culture in the case of PAC1. The multiclonal state of this culture is in agreement with a previous study investigating the variability of phycoerythrin genes within the genus Prochlorococcus (Penno et al., 2000) and has also been observed during analysis of $16 \mathrm{~S}$ rRNA sequences from other Prochlorococcus strains, such as TATL1 or
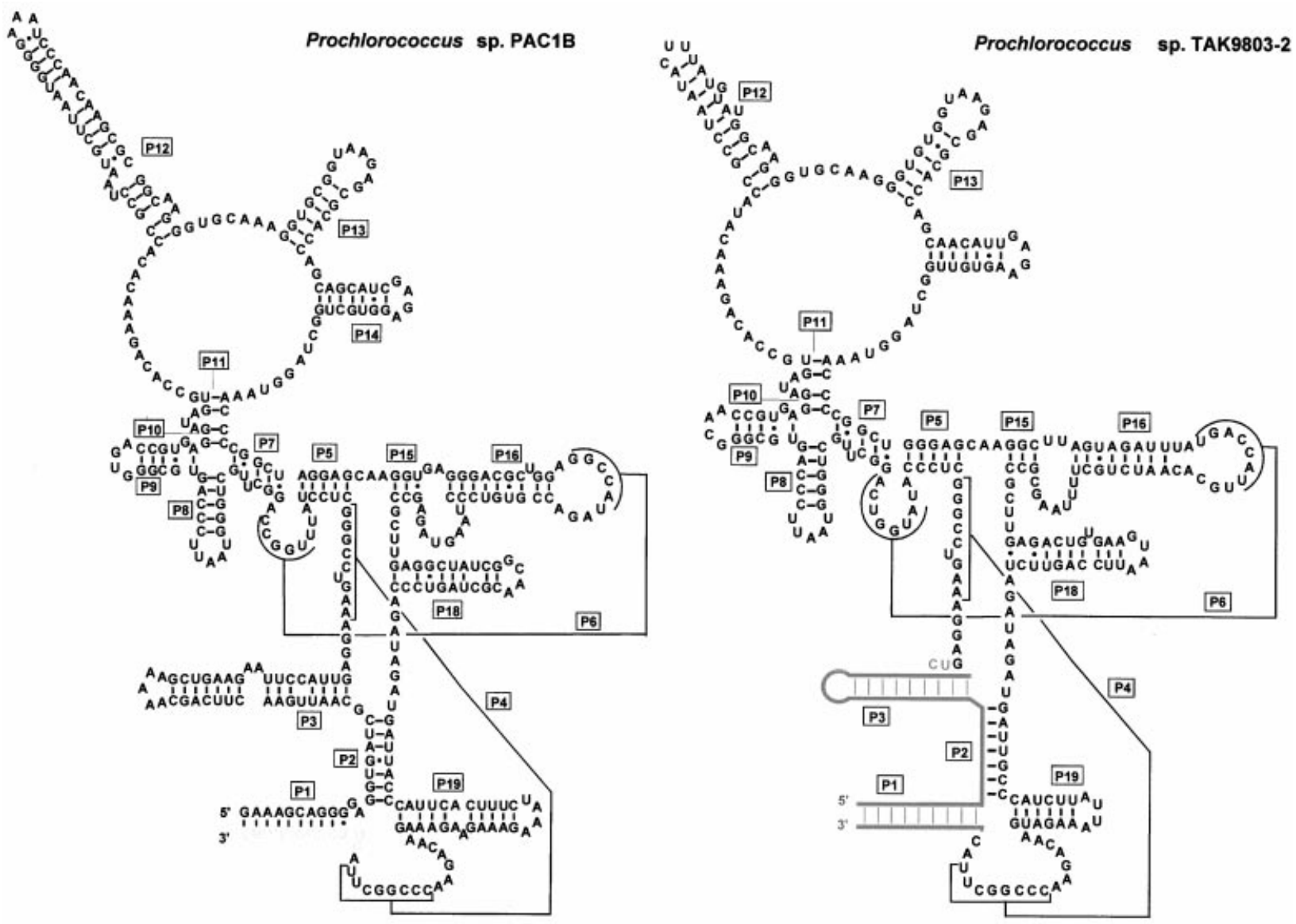

Fig. 1. RNase $P$ RNA structures. Typical structural elements of Prochlorococcus RNAs are represented. The complete structure of PAC1B RNase P RNA (the $3^{\prime}$ terminus has been deduced from the known P1 sequence and is drawn in grey) and the core structure of the TAK9803-2 RNA ( $5^{\prime}$ and $3^{\prime}$ ends were not determined and are drawn schematically in grey) are shown. 
P. marinus subsp. marinus $\mathrm{SS}_{120}{ }^{\mathrm{T}}$

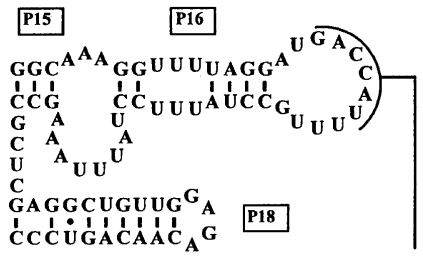

Synechococcus MINOS 1

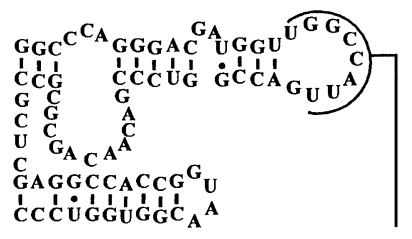

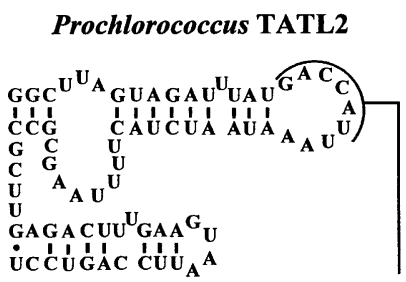

Prochlorococcus PAC1A

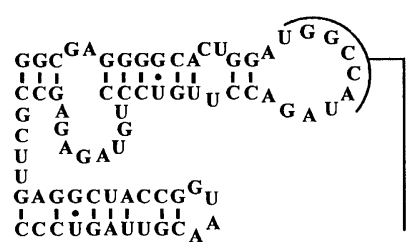

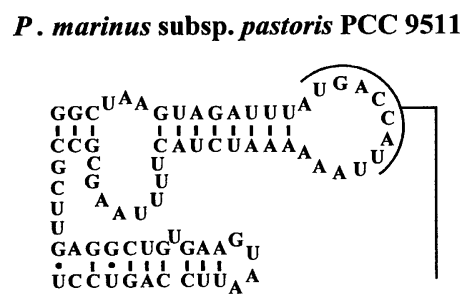

Prochlorococcus NATL1A

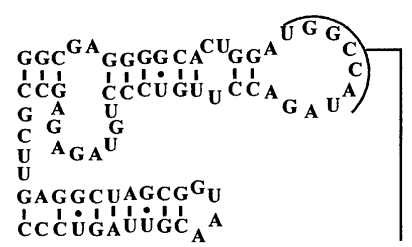

Prochlorococcus TATL1B

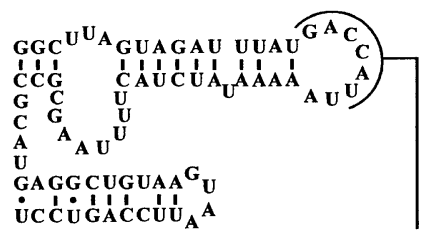

Prochlorococcus NATL2A

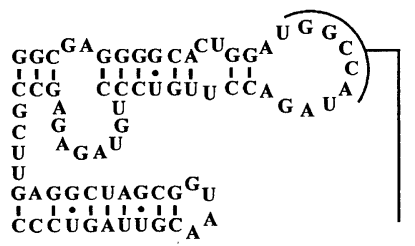

Fig. 2. Overview of structural variants within the P15/P16 and P18 domains.

NATL2. All differences between PAC1A and PAC1B can be localized to the helices P15/16, P18 and P19. In addition, the $5^{\prime}$ end of PAC1B rnpB was amplified using primers $\mathrm{Pm}-\mathrm{F}^{\prime}$ and cprp3'-OL. This experiment confirmed a genome arrangement similar to that in $\mathrm{SS} 120^{\mathrm{T}}$ (Hess et al., 1998), with a gene for tRNA ${ }^{\mathrm{Arg}}$ located immediately upstream on the complementary strand (Hess \& Schön, 1999). Interestingly, the PAC1A sequence is more similar to NATL2A than NATL2A is to NATL1A and PAC1A is to PAC1B, obtained from the same culture.

\section{Structural comparison}

Despite the high variability at the sequence level, the main structural determinants are fully conserved. The postulated secondary structures (Fig. 1) indicate clearly that all investigated RNAs belong to the cyanobacterial type (Banta et al., 1992; Fingerhut \& Schön, 1998; Pascual \& Vioque, 1994; Vioque, 1992). The long-distance base pairing P6 (Haas et al., 1994), which might be potentially extended to $6 \mathrm{bp}$ in $P$. marinus subsp. marinus SS120 ${ }^{\mathrm{T}}$ (Hess et al., 1998) and many other cyanobacterial-type RNAs (Schön, 1999), consists of only $5 \mathrm{bp}$ in the PAC1B RNA (Fig. 1). In TAK9803-2 (Fig. 1), and also in TATL1B and TATL2, P6 may be extended to $7 \mathrm{bp}$ if the distal end of P16 is opened (Fig. 2). The RNA of Synechococcus MINOS1, a closely related marine cyanobacterium, may even employ 8 bp for P6 (Fig. 2).
An important structural feature, the extended asymmetrical loop joining stems $\mathrm{P} 15$ and P16, is present in all the novel RNase P RNAs described in this paper. It has also been found in other cyanobacterial RNase P RNAs, except those of Pseudanabaena, Oscillatoria and Prochlorothrix. The corresponding domain in $E$. coli contains the canonical 5'-GGU-3' motif, binding the substrate via its $3^{\prime}$ CCA end. However, despite the obvious replacement of this binding domain by the P15/P16 loop, the pre-tRNA CCA end remains crucial for efficient turnover in Prochlorococcus, as shown previously (Hess et al., 1998). The presence of three consecutive U-U 'mismatches' in helix P16 of $P$. marinus subsp. marinus SS120 ${ }^{\mathrm{T}}$ RNase P RNA (Hess et al., 1998) is unique within the cyanobacterial group, as none of the other RNAs contains a similar stretch of unpaired nucleotides within P16 (Fig. 2). Most cyanobacterial RNase P RNAs possess a 2- to 4-base bulge within an otherwise fully paired P16, and this is exactly what was found for Prochlorococcus strains PAC1A, PAC1B, TATL1B, TATL2, NATL1A and NATL2A and Synechococcus sp. MINOS1, whereas P. marinus subsp. pastoris PCC $9511^{\mathrm{T}}$ has a fully paired P16 domain. Another peculiarity of the $P$. marinus subsp. marinus $\mathrm{SS}_{12} 0^{\mathrm{T}} \mathrm{RNA}$, an unpaired $\mathrm{U}-\mathrm{U}$ in helix P5 (Hess et al., 1998), is restricted to this species and PCC $9511^{\mathrm{T}}$, whereas $\mathrm{P} 5$ is fully paired in all other ribozyme variants.

A structural feature that correlates well with the position of the respective strains in the phylogenetic 
tree is a single bulging nucleotide in P18. This situation is observed in the RNA of the three HL-adapted strains PCC $9511^{\mathrm{T}}$, TATL2 and TAK 9803-2 and thus evolved within this group. It has no counterpart in any other bacterium except Deinococcus radiodurans (Brown, 1999).

The PAC1 culture has previously been characterized as belonging to the LL clade of Prochlorococcus (Penno et al., 2000; Urbach et al., 1998), as is the case for the type strain P. marinus subsp. marinus CCMP $1375^{\mathrm{T}}$ (equivalent to strain $\mathrm{SS} 120^{\mathrm{T}}$ ). To obtain the sequence information required to include the complete $5^{\prime}$ domain in our analysis, the $5^{\prime}$ flank of PAC1B, including part of the adjacent $\operatorname{trn} R$ gene, was amplified. From a total of 37 positions in P3, 13 differ between these two strains (Fig. 1; Hess et al., 1998). The marine Synechococcus strain MINOS1 was included in this analysis because marine Synechococcus are phylogenetically closer to Prochlorococcus than to freshwater cyanobacteria. Interestingly, its RNase P RNA structure is much more similar to that of freshwater Synechococcus PCC 6301 than to that of any Prochlorococcus: in contrast with all Prochlorococcus ribozymes, domain P19 is missing, P16 has a 'double bulge' and P6 can be potentially extended to $8 \mathrm{bp}$, both very similar to Synechococcus PCC 6301. Furthermore, P12 from MINOS1 closely resembles its counterpart from Synechococcus PCC 6301.

Fluorescent in situ hybridization of primers targeted to the 16S rRNA has recently become a powerful tool for the analysis of natural populations of phytoplankton (West \& Scanlan, 1999). RNase P RNA might constitute a potential alternative target, given its comparatively high intracellular abundance. Hence, it might be envisaged that RNase P RNA sequences may be used to determine directly the spatial and temporal distribution of particular geno- and/or ecotypes in natural populations. Based on the findings of this study and existing three-dimensional models (Chen et al., 1998; Harris et al., 1997, 1994; Westhof \& Altman, 1994; Westhof et al., 1996), P12, P18, P19 and possibly P3 are suggested as the most promising regions, by virtue of their extremely high variability and their easy accessibility, for the design of genotype-specific probes.

\section{Phylogenetic comparisons}

Phylogenetic trees based on 16S rRNA sequences have become a widely accepted standard for inferring evolutionary relationships. Their comparison to other possible markers, i.e. mainly rpoC1 (Palenik, 1994; Palenik \& Haselkorn, 1992) in the case of Prochlorococcus, has firmly confirmed the value of $16 \mathrm{~S}$ rRNA phylogenetic trees. Thus, alternative markers might be useful only if they allowed a better resolution of closely related species or the application of novel techniques. In cyanobacteria, the $16 \mathrm{~S}$ rRNA-23S rRNA internal transcribed spacer region (Iteman et al., 2000) and, within Prochlorococcus, the petB-petD

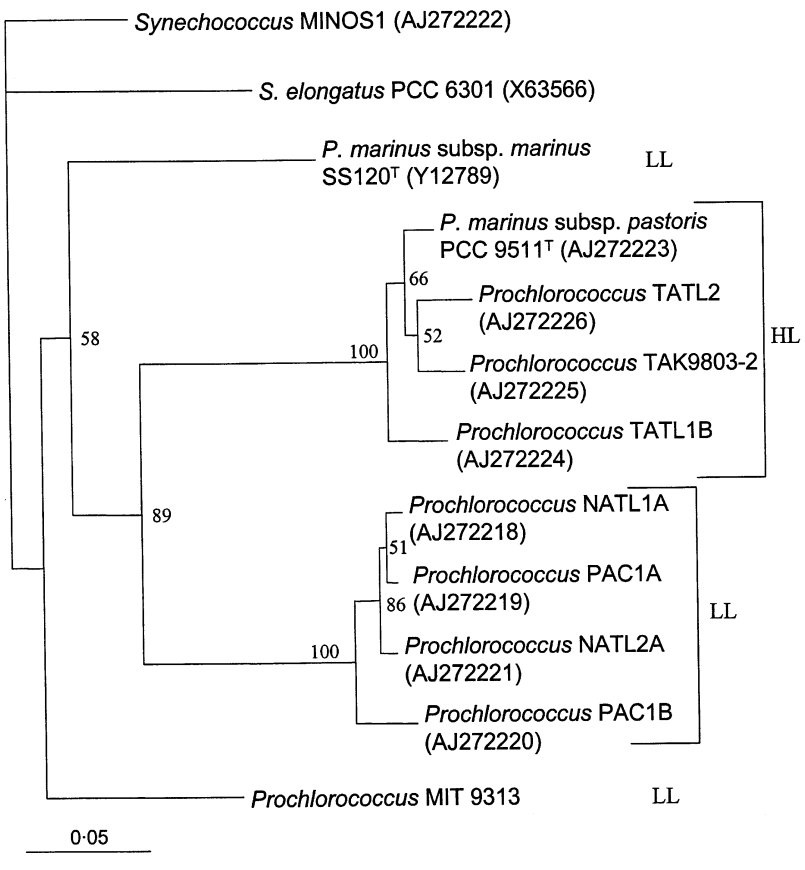

Fig. 3. Neighbour-joining phylogenetic tree. The tree was constructed using PAUP 4.0 with the optimality criterion set to distance (minimum evolution) and the two Synechococcus sequences MINOS1 and Synechococcus elongatus PCC 6301 (Banta et al., 1992) used as outgroups. It is based on an RNase P RNA sequence alignment optimized according to structural considerations (available as supplementary material in IJSEM Online at http://ijs.sgmjournals.org/), but omitting primerannealing sites as well as the hypervariable regions 218-223 and 241-275. Bootstrap values are shown inside each node (percentages of 100 bootstraps). GenBank accession numbers are given in parentheses; the sequence of Prochlorococcus MIT 9313 has not been deposited.

intergenic region (Urbach et al., 1998), have previously been investigated towards this goal. Thus, rnpB-based phylogenies might be of potential interest because of the high level of variability within the coding region. Phylogenetic trees have previously been inferred successfully from the comparison of RNase P RNA sequences of various species (Cho et al., 1998; Herrmann et al., 1996, 2000; Yoon \& Park, 2000). The sequence identity between the different $r n p B$ sequences is $74-99 \%$. Thus, these sequences are considerably less similar to each other than are $16 \mathrm{~S}$ rRNA sequences from the same organisms ( $>97 \%$; Moore et al., 1998), and a much higher level of resolution might be expected for $r n p B$-based phylogenetic trees.

A phylogenetic tree was constructed by neighbourjoining analysis with the two Synechococcus sequences as outgroups (Fig. 3). All Prochlorococcus HL strains belong to a single large cluster; the LL strains PAC1A, 1B, NATL1A and 2A fall into a second single clade, whereas the two other LL strains are located in separate places. The same basic branching order was obtained when the optimality criterion was set to maximum-likelihood or maximum-parsimony. However, in some analyses, the positions of NATL1A, 
NATL2A and PAC1A could not be resolved. In principle, the trees obtained on the basis of $\operatorname{rnpB}$ sequences are of similar topology to those constructed from rRNA sequences. The HL strains form a coherent cluster and all LL strains branch off earlier and fall into different groups. Thus, the strains cluster according to their ecophysiological and ecological characteristics, rather than their geographical sites of isolation. This supports results obtained earlier with 16S rRNA (Rocap et al., 1999; Urbach \& Chisholm, 1998) or rpoCl sequences (Palenik, 1994). The clear resolution within the two main clusters in the tree is very interesting. Among deep (LL) strains, the North Atlantic and Pacific isolates are surprisingly similar. In the tree shown in Fig. 3, the PAC1A sequence is even closer to NATL1A from the North Atlantic than to PAC1B obtained from the same culture. This suggests a remarkable genetic stability of Prochlorococcus genotypes that thrive under identical ecological conditions. Within the HL cluster, TATL2 and TAK 9803-2 represent the two most closely related forms. In 16S rRNA phylogenies, both strains have occasionally been included with additional sequences into HL cluster II, which is separate from HL cluster I containing strains PCC $9511^{\mathrm{T}}$ and TATL1B (West \& Scanlan, 1999). It is intriguing that RNase P phylogenies suggest such a possible branching of these HLII sequences from within the other HL-adapted genotypes, but further analyses including additional strains might help to substantiate this observation further.

Thus, our data show the high versatility of RNase $\mathrm{P}$ as a potential marker for the phylogeny and molecular ecology of Prochlorococcus and specifically for the investigation of closely related genotypes.

\section{ACKNOWLEDGEMENTS}

This work was supported by grants from the Deutsche Forschungsgemeinschaft to A.S. (Scho 515/4-1) and the European Union (PROMOLEC; MAS3-CT97-0128) to W. R. H. We thank R. Rippka, Paris, for providing a culture of PCC $9511^{\mathrm{T}}$, F. Partensky, Roscoff, for providing samples of MINOS1, TATL1B, TATL2B, TAK9803-2, NATL1A, NATL2A and SS120 ${ }^{\mathrm{T}}$, L. Campbell, College Station, for an aliquot of PAC1, and F. Larimer and S. W. Chisholm for permission to include the preliminary sequence data obtained from the DOE Joint Genome Institute at http:/ /www.jgi.doe.gov/JGI_microbial/html/prochlorococcus/ prochlo_pickastrain.html for Prochlorococcus strain MIT 9313.

\section{REFERENCES}

Banta, A. B., Haas, E. S., Brown, J. W. \& Pace, N. R. (1992). Sequence of the ribonuclease P RNA gene from the cyanobacterium Anacystis nidulans. Nucleic Acids Res 20, 911.

Baum, M., Cordier, A. \& Schön, A. (1996). RNase P from a photosynthetic organelle contains an RNA homologous to the cyanobacterial counterpart. J Mol Biol 257, 43-52.

Brown, J. W. (1999). The ribonuclease P database. Nucleic Acids Res 27, 314.
Brown, J. W., Nolan, J. M., Haas, E. S., Rubio, M. A., Major, F. \& Pace, N. R. (1996). Comparative analysis of ribonuclease P RNA using gene sequences from natural microbial populations reveals tertiary structural elements. Proc Natl Acad Sci U S A 93, 3001-3006.

Chen, J. L., Nolan, J. M., Harris, M. E. \& Pace, N. R. (1998). Comparative photocross-linking analysis of the tertiary structures of Escherichia coli and Bacillus subtilis RNase P RNAs. EMBO J 17, 1515-1525.

Chisholm, S. W., Frankel, S. L., Goericke, R., Olson, R. J., Palenik, B., Waterbury, J. B., West-Johnsrud, L. \& Zettler, E. R. (1992). Prochlorococcus marinus nov. gen. nov. sp.: an oxyphototrophic marine prokaryote containing divinyl chlorophyll $a$ and b. Arch Microbiol 157, 297-300.

Cho, M., Yoon, J.-H., Kim, S.-B. \& Park, Y.-H. (1998). Application of the ribonuclease P (RNase P) RNA gene sequence for phylogenetic analysis of the genus Saccharomonospora. Int J Syst Bacteriol 48, 1223-1230.

Crary, S. M., Niranjanakumari, S. \& Fierke, C. A. (1998). The protein component of Bacillus subtilis ribonuclease $\mathrm{P}$ increases catalytic efficiency by enhancing interactions with the $5^{\prime}$ leader sequence of pretRNA $^{\text {Asp }}$. Biochemistry 37, 9409-9416.

Fingerhut, C. \& Schön, A. (1998). Sequence and functional characterization of RNase P RNA from the chl a/b containing cyanobacterium Prochlorothrix hollandica. FEBS Lett 428, 161-164.

Frank, D. N. \& Pace, N. R. (1998). Ribonuclease P: unity and diversity in a tRNA processing ribozyme. Annu Rev Biochem 67, 153-180.

Garczarek, L., Hess, W. R., Holtzendorff, J., van der Staay, G. W. \& Partensky, F. (2000). Multiplication of antenna genes as a major adaptation to low light in a marine prokaryote. Proc Natl Acad Sci U S A 97, 4098-4101.

Haas, E. S., Brown, J. W., Pitulle, C. \& Pace, N. R. (1994). Further perspective on the catalytic core and secondary structure of ribonuclease P RNA. Proc Natl Acad Sci U S A 91, 2527-2531.

Harris, M. E., Nolan, J. M., Malhotra, A., Brown, J. W., Harvey, S. C. \& Pace, N. R. (1994). Use of photoaffinity crosslinking and molecular modeling to analyze the global architecture of ribonuclease $\mathrm{P}$ RNA. EMBO J 13, 3953-3963.

Harris, M. E., Kazantsev, A. V., Chen, J. L. \& Pace, N. R. (1997). Analysis of the tertiary structure of the ribonuclease P ribozymesubstrate complex by site-specific photoaffinity crosslinking. RNA $\mathbf{3}$, 561-576.

Herdman, M., Castenholz, R. W., Iteman, I., Waterbury, J. B. \& Rippka, R. (2001). Subsection I. (formerly Chroococcales Wettstein 1924, emend. Rippka, Deruelles, Waterbury, Herdman and Stanier 1979). In Bergey's Manual of Systematic Bacteriology, 2nd edn, vol. 1, The Archaea and Deeply Branching and Phototrophic Bacteria, pp. 493-514. Edited by D. R. Boone, R. W. Castenholz \& G. M. Garrity. New York: Springer.

Herrmann, B., Winqvist, O., Mattsson, J. G. \& Kirsebom, L. A. (1996). Differentiation of Chlamydia spp. by sequence determination and restriction endonuclease cleavage of RNase P RNA genes. J Clin Microbiol 34, 1897-1902.

Herrmann, B., Pettersson, B., Everett, K. D. E., Mikkelsen, N. E. \& Kirsebom, L. A. (2000). Characterization of the $r n p B$ gene and RNase P RNA in the order Chlamydiales. Int J Syst Evol Microbiol 50, 149-158.

Hess, W. R. \& Schön, A. (1999). Characterization of $r n p B$, the gene encoding the RNA component of RNase $\mathrm{P}$ of Prochlorococcus marinus. In Marine Cyanobacteria, vol. 19, pp. 77-82. Edited by L. Charpy \& A. W. D. Larkum. Monaco: Musée Océanographique.

Hess, W. R., Fingerhut, C. \& Schön, A. (1998). RNase P RNA from Prochlorococcus marinus: contribution of substrate domains to recognition by a cyanobacterial ribozyme. FEBS Lett 431, 138-142.

Iteman, I., Rippka, R., Tandeau de Marsac, N. \& Herdman, M. (2000). Comparison of conserved structural and regulatory domains within divergent $16 \mathrm{~S}$ rRNA-23S rRNA spacer sequences of cyanobacteria. Microbiology 146, 1275-1286. 
Moore, L. R., Rocap, G. \& Chisholm, S. W. (1998). Physiology and molecular phylogeny of coexisting Prochlorococcus ecotypes. Nature 393, 464-467.

Niranjanakumari, S., Stams, T., Crary, S. M., Christianson, D. W. \& Fierke, C. A. (1998). Protein component of the ribozyme ribonuclease $\mathrm{P}$ alters substrate recognition by directly contacting precursor tRNA. Proc Natl Acad Sci U S A 95, 15212-15217.

Pace, N. R. \& Brown, J. W. (1995). Evolutionary perspective on the structure and function of ribonuclease $\mathrm{P}$, a ribozyme. J Bacteriol 177, 1919-1928.

Palenik, B. (1994). Cyanobacterial community structure as seen from RNA polymerase gene sequence analysis. Appl Environ Microbiol 60, 3212-3219.

Palenik, B. \& Haselkorn, R. (1992). Multiple evolutionary origins of prochlorophytes, the chlorophyll b-containing prokaryotes. Nature 355, 265-267.

Partensky, F., Hess, W. R. \& Vaulot, D. (1999). Prochlorococcus, a marine photosynthetic prokaryote of global significance. Microbiol Mol Biol Rev 63, 106-127.

Pascual, A. \& Vioque, A. (1994). Sequence and structure of the RNA subunit of RNase P from the cyanobacterium Pseudoanabaena sp. PCC6903. Biochim Biophys Acta 1218, 463-465.

Penno, S., Campbell, L. \& Hess, W. R. (2000). Presence of phycoerythrin in two strains of Prochlorococcus (Cyanobacteria) isolated from the subtropical north Pacific Ocean. J Phycol 36, 723-729.

Rippka, R., Coursin, T., Hess, W. \& 7 other authors (2000). Prochlorococcus marinus Chisholm et al. 1992 subsp. pastoris subsp. nov. strain PCC 9511, the first axenic chlorophyll $a_{2} / b_{2}$-containing cyanobacterium (Oxyphotobacteria). Int J Syst Evol Microbiol 50, $1833-1847$.
Rocap, G., Moore, L. R. \& Chisholm, S. W. (1999). Molecular phylogeny of Prochlorococcus ecotypes. In Marine Cyanobacteria, vol. 19, pp. 107-116. Edited by L. Charpy \& A. W. D. Larkum. Monaco: Musée Océanographique.

Scanlan, D. J., Hess, W. R., Partensky, F., Scanlan, J. \& Vaulot, D. (1996). High degree of genetic variation in Prochlorococcus (Prochlorophyta) revealed by RFLP analysis. Eur J Phycol 31, 1-9.

Schön, A. (1999). Ribonuclease P: the diversity of a ubiquitous RNA processing enzyme. FEMS Microbiol Rev 23, 391-406.

Urbach, E. \& Chisholm, S. W. (1998). Genetic diversity in Prochlorococcus populations flow cytometrically sorted from the Sargasso Sea and the Gulf Stream. Limnol Oceanogr 43, 1615-1630.

Urbach, E., Scanlan, D. J., Distel, D. L., Waterbury, J. B. \& Chisholm, S. W. (1998). Rapid diversification of marine picophytoplankton with dissimilar light-harvesting structures inferred from sequences of Prochlorococcus and Synechococcus (Cyanobacteria). J Mol Evol 46, 188-201.

Vioque, A. (1992). Analysis of the gene encoding the RNA subunit of ribonuclease $\mathrm{P}$ from cyanobacteria. Nucleic Acids Res 20, 6331-6337.

West, N. J. \& Scanlan, D. J. (1999). Niche-partitioning of Prochlorococcus populations in a stratified water column in the eastern North Atlantic ocean. Appl Environ Microbiol 65, 2585-2591.

Westhof, E. \& Altman, S. (1994). Three-dimensional working model of M1 RNA, the catalytic RNA subunit of ribonuclease P from Escherichia coli. Proc Natl Acad Sci U S A 91, 5133-5137.

Westhof, E., Wesolowski, D. \& Altman, S. (1996). Mapping in three dimensions of regions in a catalytic RNA protected from attack by an Fe(II)-EDTA reagent. J Mol Biol 258, 600-613.

Yoon, J.-H. \& Park, Y.-H. (2000). Comparative sequence analyses of the ribonuclease P (RNase P) RNA genes from LL-2,6-diaminopimelic acid-containing actinomycetes. Int J Syst Evol Microbiol 50, 2021-2029. 